\title{
Targeting S100B with Peptides Encoding Intrinsic Aggregation-Prone Sequence Segments
}

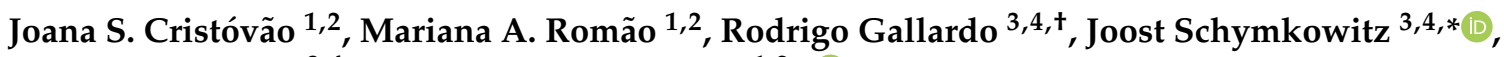 \\ Frederic Rousseau ${ }^{3,4, *}$ and Cláudio M. Gomes ${ }^{1,2, * \mathbb{D}}$ \\ 1 Biosystems and Integrative Sciences Institute, Faculdade de Ciências, Universidade Lisboa, \\ 1749-016 Lisbon, Portugal; jmcristovao@fc.ul.pt (J.S.C.); maromao@fc.ul.pt (M.A.R.) \\ 2 Departamento de Química e Bioquímica, Faculdade de Ciências, Universidade Lisboa, \\ 1749-016 Lisbon, Portugal \\ 3 VIB Switch Laboratory, Flanders Institute for Biotechnology (VIB), 3000 Leuven, Belgium; \\ rodrigo.gallardo@switch.vib-kuleuven.be \\ 4 Switch Laboratory, Department of Cellular and Molecular Medicine, KU Leuven, Herestraat 49, PB 802, \\ 3000 Leuven, Belgium \\ * Correspondence: cmgomes@fc.ul.pt (C.M.G.); frederic.rousseau@kuleuven.vib.be (F.R.); \\ joost.schymkowitz@kuleuven.vib.be (J.S.) \\ + Current address: Astbury Centre for Structural Molecular Biology, School of Molecular and Cellular Biology, \\ University of Leeds, Leeds LS2 9JT, UK.
}

Citation: Cristóvão, J.S.; Romão, M.A.; Gallardo, R.; Schymkowitz, J.; Rousseau, F.; Gomes, C.M. Targeting S100B with Peptides Encoding Intrinsic Aggregation-Prone Sequence Segments. Molecules 2021, 26, 440. https://doi.org/10.3390/

molecules 26020440

Academic Editor: Rosario

Francesco Donato

Received: 19 December 2020

Accepted: 12 January 2021

Published: 15 January 2021

Publisher's Note: MDPI stays neutral with regard to jurisdictional claims in published maps and institutional affiliations.

Copyright: (c) 2021 by the authors. Licensee MDPI, Basel, Switzerland. This article is an open access article distributed under the terms and conditions of the Creative Commons Attribution (CC BY) license (https:// creativecommons.org/licenses/by/ $4.0 /)$.

\begin{abstract}
S100 proteins assume a diversity of oligomeric states including large order self-assemblies, with an impact on protein structure and function. Previous work has uncovered that S100 proteins, including $\mathrm{S100B}$, are prone to undergo $\beta$-aggregation under destabilizing conditions. This propensity is encoded in aggregation-prone regions (APR) mainly located in segments at the homodimer interface, and which are therefore mostly shielded from the solvent and from deleterious interactions, under native conditions. As in other systems, this characteristic may be used to develop peptides with pharmacological potential that selectively induce the aggregation of S100B through homotypic interactions with its APRs, resulting in functional inhibition through a loss of function. Here we report initial studies towards this goal. We applied the TANGO algorithm to identify specific APR segments in S100B helix IV and used this information to design and synthesize S100B-derived APR peptides. We then combined fluorescence spectroscopy, transmission electron microscopy, biolayer interferometry, and aggregation kinetics and determined that the synthetic peptides have strong aggregation propensity, interact with S100B, and may promote co-aggregation reactions. In this framework, we discuss the considerable potential of such APR-derived peptides to act pharmacologically over S100B in numerous physiological and pathological conditions, for instance as modifiers of the S100B interactome or as promoters of S100B inactivation by selective aggregation.
\end{abstract}

Keywords: S100 proteins; protein aggregation; amyloid; protein biophysics; structural biology

\section{Introduction}

S100 proteins are a family of EF-hand $\mathrm{Ca}^{2+}$-binding signaling proteins that have evolved in vertebrates to carry out a multitude of functions related to proliferation, differentiation, cell apoptosis, migration, energy metabolism, calcium homeostasis, and inflammation, under physiological and pathological conditions [1,2]. These small ( 12 kDa) dimeric proteins are extremely versatile, and their biological activity is regulated by expression levels, metalation state, cellular location (intra vs extracellular), and quaternary structure and assembly state [3,4]. Notably, S100B is one of the S100 proteins that has been implicated in cancer and in neurodegenerative diseases, and therefore there is ample interest in the pharmacological modulation of its activity $[5,6]$.

Compounds such as pentamidine have promising therapeutic activities as inhibitors of S100B function in multiple pathological scenarios [7,8]. For instance, pentamidine in- 
hibits the interaction between p53 and S100B, thus reactivating the transcriptional activity of p53 apoptosis in cancer cells; also, pentamidine decreases gliosis and neuroinflammation in a mouse model of $A \beta$-induced Alzheimer's Disease (AD) suggesting an inhibitory activity over the interaction between S100B and RAGE (receptor for advanced glycation end-products) [9], similarly to other S100 proteins [10]. Also, S100B protein functions are frequently concentration-dependent, being protective at low concentrations and deleterious at high levels. The involvement of S100B in AD is one such example: in late disease stages when it is overexpressed and secreted by astrocytes, S100B acts as a pro-inflammatory cytokine that promotes gliosis and aggravates neuroinflammation as a response to the accumulation of amyloid beta deposits [11]; however, at earlier inflammatory stages, when the relative levels of $\mathrm{A} \beta 42$ and S100B are still increasing, S100B exerts a protective chaperone-like activity engaging in interactions with $A \beta 42$ that inhibit its aggregation and mitigate amyloid toxicity $[12,13]$. It is therefore also useful to have drugs that are not only able to completely inhibit S100B activities but that are also able to regulate its levels in cells.

In this respect, approaches based on the use of aggregation-prone peptides as tools to selectively inactive or modulate the levels of a given target protein, hold the potential to develop such sophisticated therapeutic biologics. The strategy of selective aggregation of globular proteins mediated by peptides is based on aggregation seeding, which is a process driven by so-called aggregation-prone regions (APRs). These are short amino acid stretches that are present across proteomes [14] and which dictate the propensity for $\beta$-aggregation being extensively found in globular proteins [15]. These APRs engage in homotypic interactions resulting in the formation of tightly packed intermolecular amyloid structures. Synthetic biology approaches have demonstrated that peptides derived from APRs present in a given protein are able to interact selectively with that specific protein, causing its inactivation through aggregation. This approach has been established in several systems, and examples include the use of APRs to generate selective knockdowns in plants [16] or as anti-bacterial agents with antibiotic properties in bacteria, but not in infected mammalian cells [17].

S100 proteins are amenable targets to develop APR-based functional modulators with pharmacological potential. Previous reports showed that S100 proteins have aggregationprone regions at the dimer interface that are flanked by intrinsically disordered regions $[18,19]$. Upon destabilization, these regions become solvent-exposed, homotypic interactions take place and $\beta$-aggregation evolves [20,21]. Here, we explore this property to design, synthesize, and characterize APR peptides inspired in S100B, as a first approach towards the future development of pharmacologically active biologics capable of targeting and modulating S100B levels and functions. For this, we developed a mini library of three peptides inspired in APRs within helix IV of S100B, which we characterized with respect to their aggregation propensities, interaction with S100B, and in vitro co-aggregation.

\section{Results and Discussion}

\subsection{S100B-Derived APR Peptides: Design and Synthesis}

We employed TANGO, a statistical algorithm for predicting aggregation-prone sequences [22], to analyze the sequence of human S100B and determined that the region with the highest aggregation propensity locates within helix IV, in residues 73 to 85 (Figure 1). Flaking this segment are two glutamate residues (Glu-72 and Glu-86), which act as gatekeepers. Aggregation gatekeepers are residues observed at the sides of these aggregation-prone sequence segments that protect from aggregation [15,23,24]; such residues are frequently charged and counteract aggregation through repulsive effects. We used the information from TANGO to identify sequences that comprise at least six successive amino acids with high aggregation scores, which guided the design of four representative peptides within this region (Figure 1c). Each APR-S100B peptide is composed of a PEG2-biotin and two identical repeats of the $\beta$-aggregating sequence flanked by different gatekeeper residues that act as solubilizing moieties. The aim of including tandem sequences was to amplify 
the aggregation potential by repeating APR patterns. In the designed APR-S100B peptides, which were inspired in sequences at the beginning of helix IV (Pep4 to 6), we made variants that include not only the natural gatekeeper (Glu) but also other charged residues (Asp and Arg). Including gatekeepers in these constructs is critical for harnessing the aggregation potential through charge repulsions, as otherwise, the APR-S100B peptides would promptly fibrillate, rendering them of little use to establish regulatory interactions with the S100B target. One additional peptide corresponding to the last stretch of helix IV was also synthesized to further scan this region (Pep11). This peptide has the lowest TANGO aggregation score and thus serves also as a control. It is important to note that the reason for which we did not synthesize peptides with no gatekeeper residues is that such peptides would not be suitable controls as they would form stable amyloid fibrils even faster [15], and therefore would not be available to engage in homotropic interactions with helix IV in S100B, as we seek to test. All peptides were obtained by solid phase peptide synthesis at good yields and purity, as analyzed by High-performance liquid chromatography (HPLC) (Figure S1).
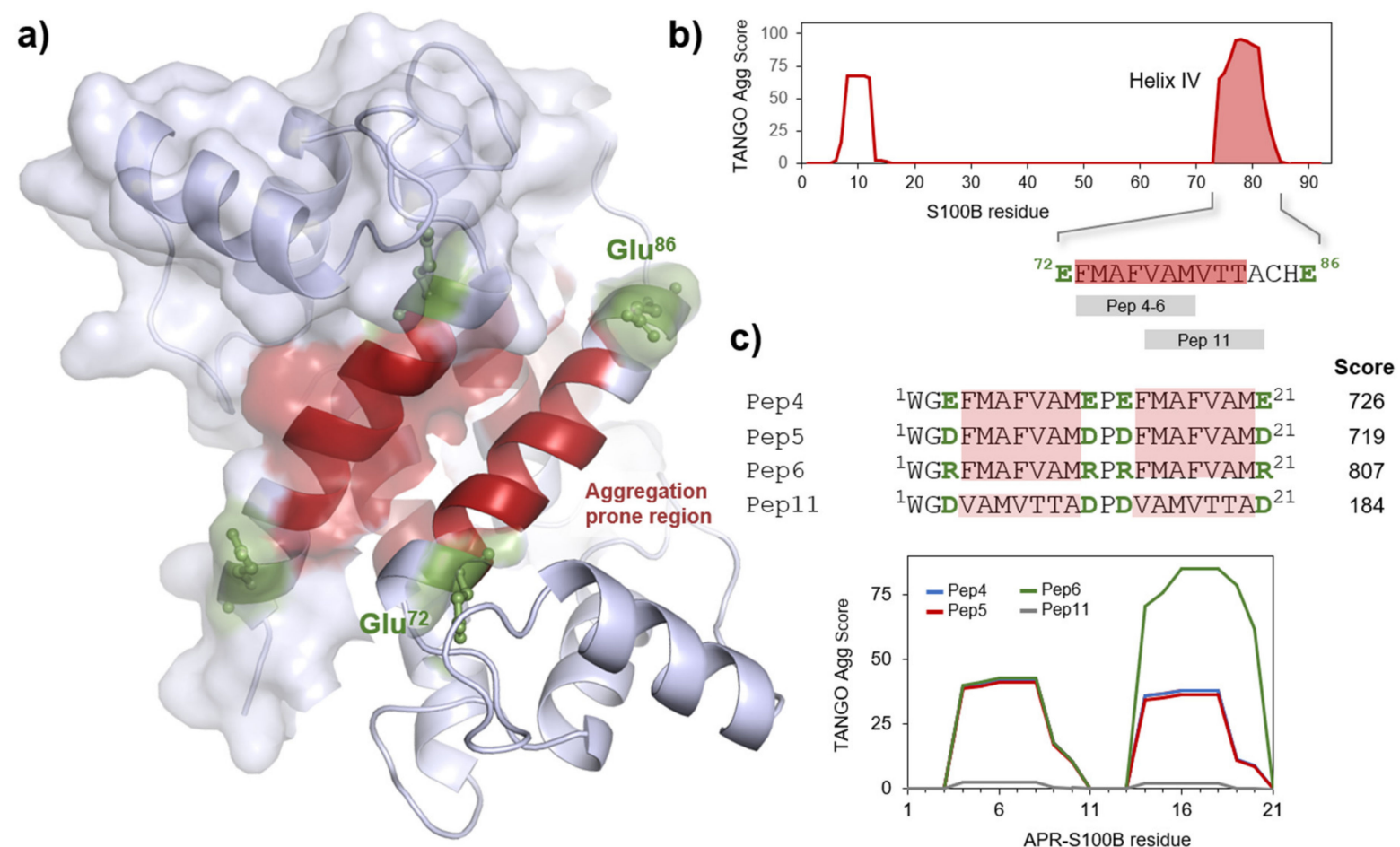

Figure 1. S100B structure and designed aggregation-prone peptides. (a) Structure of the human S100B dimer with the aggregation-prone helix IV marked in red and its capping Glu gatekeeper residues depicted in green; one of the subunits is marked with surface contour. Figure made with Pymol [25] based on the Protein Data Bank (PDB) entry 3d0y; (b) Plot of TANGO scores of human S100B, highlighting helix IV and its APR sequence; (c) Sequence of the designed APR-S100B peptides with the tandem APR highlighted in red, gatekeepers in bold green and plots of TANGO scores.

\subsection{Aggregation Propensity of S100B-Derived APR Peptides}

We then proceeded with the characterization of the aggregation propensity of the synthesized peptides to test if the computed aggregation propensity translates into the formation of fibrillar aggregates. After solubilization and filtration, all the peptides were polydispersed in a solution while kept in ice. However, they become more polydisperse over time suggesting that the formation of aggregates took place. We resorted to thioflavin$\mathrm{T}$ (ThT) fluorescence emission to monitor if the formed aggregates have an amyloidogenic character, as ThT is a well-established fluorescent reporter for cross $\beta$-rich aggregates [26]. For this, we incubated APR-S100B peptides $(200 \mu \mathrm{M})$ in $50 \mathrm{mM}$ (4-(2-hydroxyethyl)-1piperazineethanesulfonic acid) (HEPES) $\mathrm{pH} 7.4$ at room temperature for up to $24 \mathrm{~h}$ and 
determined that only two peptides are clearly ThT positive (Pep4 and Pep5). Given the high aggregation propensity encoded within most of these sequences, we hypothesized that lack of ThT binding might indicate that the peptides would be forming polymorphic fibrils that might be undetected by ThT, whose limitations are well known. We thus tested heptamerformyl thiophene acetic acid (h-FTAA), which is a dye from the family of luminescent conjugated oligothiophenes (LCOs) [27], that is known to recognize multiple types of $\beta$-aggregates. Indeed, Pep6 tested positive for this fluorophore suggesting that it forms a different type of amyloid morphotype. On the other hand, Pep11 was negative for both ThT and h-FTAA, in agreement with its low aggregation propensity score. To investigate fibril structure further, we employed transmission electron microscopy (TEM) to analyze the morphology of aggregates formed by the APR-S100B peptides at identical concentrations $(200 \mu \mathrm{M})$ and incubation times $\left(24 \mathrm{~h}\right.$ at $\left.37^{\circ} \mathrm{C}\right)$ (Figure 2). We noted that, indeed, the analyzed peptides form aggregates with different morphologies as a result of polymorphic variability. APR-S100B-Pep4 forms thick amyloid-like fibers denoting some twisting which seems to result from side-by-side adhesion of fibrils (Figure 2a). APR-S100B-Pep5 and Pep6 form smaller and thinner fibers (Figure $2 b, c)$ while Pep11 generates amorphous aggregates. This confirms that the APR-S100B peptides derived from S100B helix IV core (Pep4 to Pep6) are highly amyloidogenic, while the control APR-S100B-Pep11 peptide, which has a low aggregation score, does not form organized self-assemblies. Amyloid fibrils are known to be highly polymorphic and heterogeneous, and studies in bulk such as those by TEM in which multiple morphological subtypes of fibrils that are present necessarily translate this aspect. The observed differences in the fibril morphology and binding of amyloid-sensitive dyes illustrate the relevance of gatekeeper residues in determining peptide self-assembly as well as the morphology of the formed fibrillar materials, establishing that S100B-APR Pep 4, 5, and 6 are fibril forming, in agreement with TANGO predictions.

a)

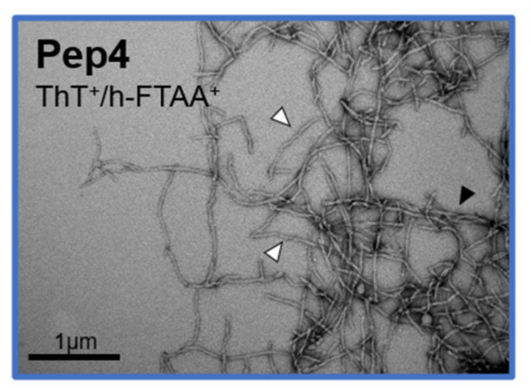

c)

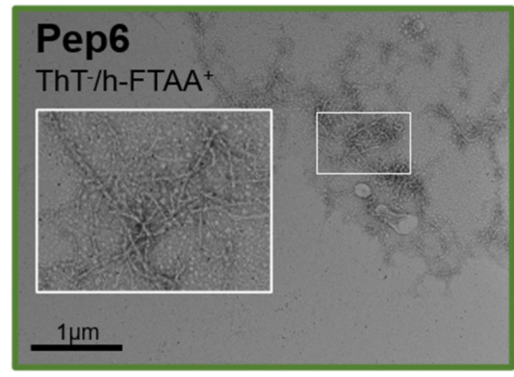

b)

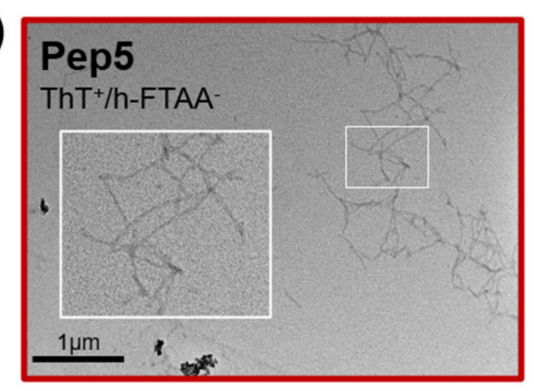

d)

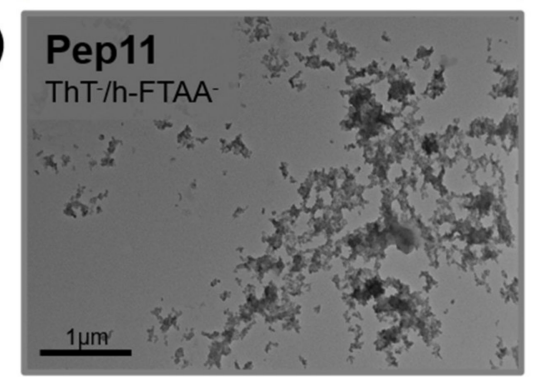

Figure 2. Transmission electron microscopy of aggregates formed by APR-S100B peptides. (a) APRScheme 100. B-Pep4, black arrowhead denotes fibril side stacking and white arrowheads illustrate twisted fibrils; (b) APR-S100B-Pep5; (c) APR-S100B-Pep6 and (d) APR-S100B-Pep11. White boxes indicate magnifications illustrating details of fibril networks. Superscripts + and - in ThT and h-FTAA indicate, respectively, positivity or negativity of aggregates in respect to these amyloiddetecting dyes. Aggregates were generated following incubation of peptides $(200 \mu \mathrm{M})$ for $24 \mathrm{~h}$ at $37^{\circ} \mathrm{C}$. 


\subsection{APR-Peptides Bind to S100B, which Modulates Their Aggregation Propensity}

To establish the potential use of APR-S100B peptides as modulators of S100B function, we first investigated if the peptides bind S100B and then if S100B influences their aggregation. To further characterize the interaction between the APR peptides and S100B, we employed biolayer interferometry (BLI), which is a label-free optical technique for measuring macromolecular interactions through the analysis of interference patterns of white light reflected from the surface of a biosensor tip to which one of the ligands is attached [28]. This technique allows thus to infer interactions by assessing the kinetics of binding and dissociation by measuring the shift (in $\mathrm{nm}$ ) in the interference pattern during the interaction. We used high precision Streptavidin biosensors to record the interaction of S100B to the biotinylated peptide (Figure 3a). In a typical experiment, the biotinylated peptide is bound to the biosensor, which is washed to remove the excess of unbound peptide and then dipped into a protein solution to determine the binding kinetics, followed by a dissociation step versus buffer. Since some aggregation of APR-S100B peptides during the time course of the BLI experiments could not be excluded, estimation of binding affinities was not pursued, as this would require accurate concentration-dependence studies. The goal of the BLI experiment was thus to demonstrate that the APR-S100B peptides with high TANGO scores do interact with S100B, in a single condition, in excess of peptides and S100B. For this, we optimized an assay using tetrameric S100B as it generated larger amplitudes of binding than the dimer (Figure $3 b$ ). Both forms are physiologically relevant and have similar exposure of the corresponding segments in helix IV [29], which allow templated binding with the synthetic peptides under study. Using this approach, we determined that Pep4, Pep5, and Pep6 bind to S100B with comparable amplitudes denoting a strong interaction, while decreased binding of Pep11 to S100B is observed, as expected for a control peptide with a low TANGO score.

a)

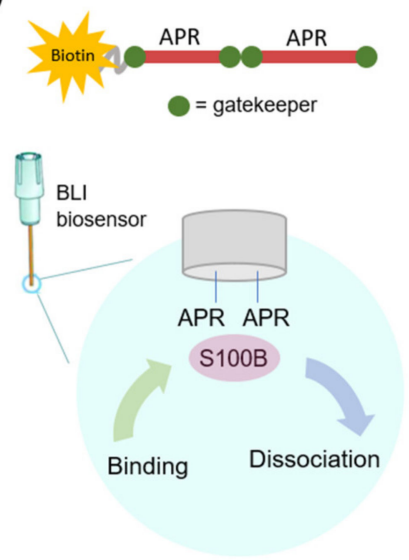

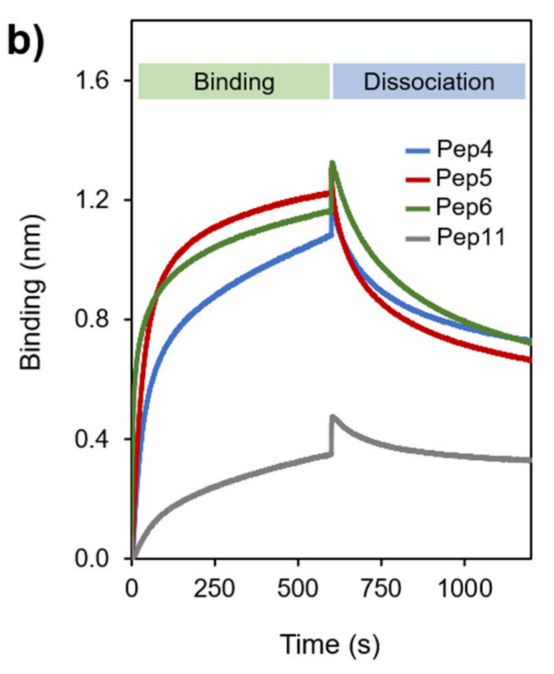

Figure 3. Biolayer interferometry analysis of the interaction between APR peptides and S100B. (a) The synthetic APR-S100B peptides were C-terminal acetylated and linked to a PEG-biotin tag which served to link the peptides to a streptavidin BLI biosensor; (b) BLI binding interferograms representative of at least 3 independent traces. Experiments were carried out at a fixed S100B concentration $(50 \mu \mathrm{M})$ with $50 \mathrm{mM}$ HEPES pH 7.4, $150 \mathrm{mM} \mathrm{NaCl}, 0.01 \%$ Tween 20 at $25^{\circ} \mathrm{C}$.

We then tested if the interaction between the APR-peptides and S100B might induce its aggregation. This is an important feature to establish if these peptides can be employed as non-genetic knockouts of S100B by causing its selective inactivation through targeted aggregation, as established for other systems [16,17]. To test this possibility, we carried out ThT-monitored aggregation kinetics experiments of $35 \mu \mathrm{M}$ APR-S100B peptides Pep4, Pep5, and Pep6 in the absence and in the presence of equimolar S100B, during $25 \mathrm{~h}$ (Figure 4). $\mathrm{S} 100 \mathrm{~B}$ does not bind ThT and its fluorescence intensity does not change over time, as previously reported [12]. 

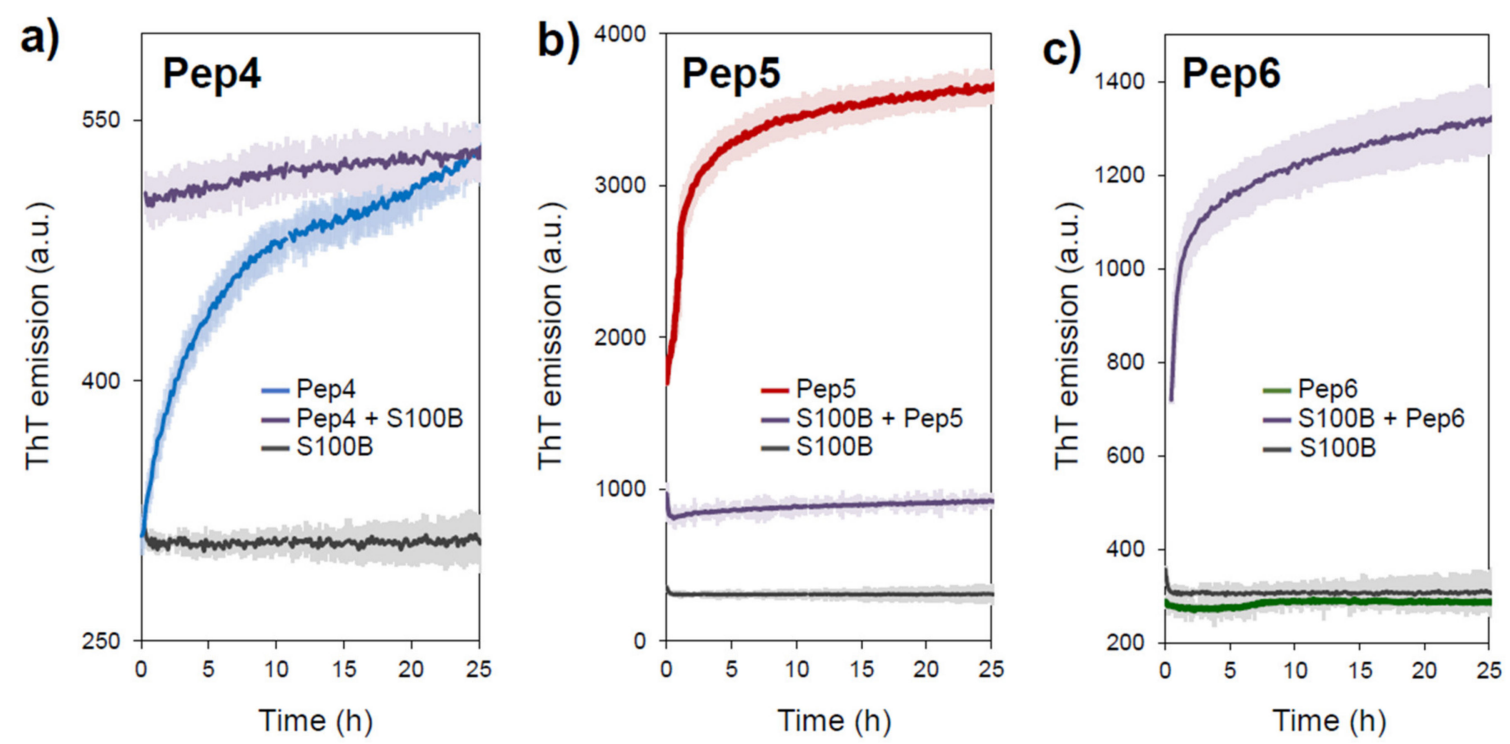

Figure 4. Aggregation kinetics of APR-S100B peptides in the presence of S100B. The time course of ThT emission was recorded as a function of time for (a) APR-S100B-Pep4, (b) APR-S100B-Pep5, (c) APR-S100B-Pep6 at $35 \mu$ M for each peptide in $50 \mathrm{mM}$ HEPES pH 7.4 at $37^{\circ} \mathrm{C}$ with agitation at $86 \mathrm{rpm}$, in the absence and in the presence of equimolar S100B. Traces depict averaged curves of 3 independent experiments with standard deviation marked as colored shades.

The peptide APR-S100B-Pep4 promptly forms ThT positive aggregates, with no lag phase, as expected for a highly amyloidogenic fragment, and ThT emission reaches a plateau approximately above $10 \mathrm{~h}$. Interestingly, the presence of S100B results in an instantaneous increase in ThT fluorescence, at levels comparable to those of the plateau stage reached in its absence, suggesting that the S100B:Pep4 interaction enhances the formation of aggregates (Figure 4a). The same sharp increase in ThT emission is observed in the aggregation kinetics of APR-S100B-Pep5 but, in this case, the presence of S100B abolishes aggregation (Figure $4 \mathrm{~b}$ ). This observation is compatible with an inhibitory interaction between Pep5 and S100B that mitigates the formation of ThT positive fibrillar materials. These observations are compatible with previous ThT fluorescence emission and TEM data (Figure 2). A very interesting effect is observed with peptide APR-S100B-Pep6: we observed that this peptide is ThT negative although it forms fibrillar materials (Figure 2c) and this is consistently observed in the aggregation kinetics (Figure 4c). However, the combination of APR-S100B-Pep6 with S100B results in the formation of ThT positive aggregates (Figure 4c). This observation is compatible with co-aggregation phenomena described for other models, in which APR peptides can selectively aggregate the proteins from which they were derived.

\section{Materials and Methods}

\subsection{S100B Expression and Purification}

All reagents were of the highest grade commercially available. A Chelex resin (BioRad, Amadora, Portugal) was used to remove contaminant trace metals from all solutions. Human S100B was expressed in E. coli (BL21 DE3) cells and purified to homogeneity using previously established protocol [30]. ApoS100B was prepared with incubation at $37^{\circ} \mathrm{C}$ for $2 \mathrm{~h}$ with a 300-fold excess of Dithiothreitol (DTT) and $0.5 \mathrm{mM}$ Ethylenediamine tetraacetic acid (EDTA) and eluted in a Superdex S75 Tricorn (GE Healthcare, Oeiras, Portugal) with $50 \mathrm{mM}$ Tris Chelex pH 7.4.

\subsection{Peptide Design and Synthesis}

The $\beta$-aggregation-prone sequences were identified using TANGO. The criteria for selecting the two regions were the following: (a) the peptide stretch should have at least six successive amino acids with a TANGO score $>5$ and (b) the total score of the selected 
window should exceed $>50$, highly indicating APRs. The C-termini of these peptides were acetylated and linked to a PEG-biotin tag. Peptides were synthesized on an Applied Biosystems 430A synthesizer (Life Technologies Corp., Carlsbad, CA, USA) according to standard procedures or on a Hamilton Microlab 2200 (Hamilton, Reno, NV, USA) using Fmoc/2"-(1H-benzotriazole-1-yl)-1,1,3,3-tetramethyluronium hexafluorophosphate (HBTU) chemistry [31]. The purity of the synthesized peptides was assessed by HPLC. Peptides were routinely solubilized in $100 \mu \mathrm{L}$ of $100 \mathrm{mM}$ Ammonium Hydroxide, $150 \mu \mathrm{L}$ of $50 \mathrm{mM}$ HEPES pH 7.2 and $100 \mu \mathrm{L}$ of $50 \mathrm{mM}$ Acetic acid, and filtered. All peptide manipulations were done at $-4{ }^{\circ} \mathrm{C}$. Peptide concentration was measured by absorbance spectroscopy using an estimated $\varepsilon(280 \mathrm{~nm})=5500 \mathrm{M}^{-1} \mathrm{~cm}^{-1}$.

\subsection{Fluorescence Spectroscopy}

Fluorescence emission intensity of the APR-S10 peptides was measured in a plate reader (BMG, Fluostar Optima, Ortenberg, Germany) using the following fluorophores and conditions: ThT $\left(\lambda_{\mathrm{exc}}=440 \mathrm{~nm}\right.$ and $\left.\lambda_{\mathrm{em}}=480 \mathrm{~nm}\right)$ and h-FTAA $\left(\lambda_{\mathrm{exc}}=480 \mathrm{~nm}\right.$ and $\lambda_{\mathrm{em}}$ $=520 \mathrm{~nm}$ ). For the analysis of ThT aggregation kinetics, peptides at $35 \mu \mathrm{M}$ were incubated at $37^{\circ} \mathrm{C}$ for up to $25 \mathrm{~h}$, in $50 \mathrm{mM}$ HEPES $\mathrm{pH} 7.4$ with agitation at $86 \mathrm{rpm}$ for $20 \mathrm{~s}$ before each cycle. S100B was also added at $35 \mu \mathrm{M}$. Real-time ThT fluorescence at $480 \mathrm{~nm}$ was recorded using a BMG Fluostar Optima (Ortenberg, Germany) fluorescence plate reader upon excitation at $440 \mathrm{~nm}$.

\subsection{Transmission Electron Microscopy (TEM)}

For each sample, $7 \mu \mathrm{L}$ aliquots of peptides, typically at 5\% APR-S100B, were adsorbed for 1 min to formvar film coated on 400-mesh copper grids (Agar Scientific Ltd., Essex, UK), washed with water five times, and stained by contact with $2 \%$ uranyl acetate. The grids were examined using a JEM-2100 transmission electron microscope (Jeol, Tokyo, Japan) at $80 \mathrm{keV} .3 .5$.

\subsection{Bio-Layer Interferometry (BLITZ)}

Protein:peptide interaction studies were performed on a Blitz instrument (ForteBio, Portsmouth, UK). The assays were done in $50 \mathrm{mM}$ HEPES pH 7.4, $150 \mathrm{mM} \mathrm{NaCl}$, $0.01 \%$ Tween 20 at $25^{\circ} \mathrm{C}$ and $1000 \mathrm{rpm}$. High precision Streptavidin biosensors (ForteBio, Portsmouth, UK) were used to record the interaction between S100B and the biotinylated peptides. A typical experiment consisted of the following steps: initial baseline for $30 \mathrm{~s}$ with the buffer; loading of biotinylated peptide to the biosensor for $120 \mathrm{~s}$, followed by $180 \mathrm{~s}$ in buffer to remove the excess of peptide unbound to the sensor. Next, the sensor was dipped in a solution of S100B tetramer $(50 \mu \mathrm{M})$ for the association step for $600 \mathrm{~s}$ and followed by dissociation with buffer for $600 \mathrm{~s}$.

\section{Conclusions}

Given its involvement in several pathologies, S100B represents a unique potential target for pharmacological intervention. Indeed, there are several reported small molecule inhibitors such as pentamidine and heptamidine that target S100B and can modulate its biological function. Here we present a preliminary study on the development of peptides containing tandem repeats of APRs derived from S100B that can selectively target the protein and modulate its function through selective co-aggregation. We showed that the designed APR peptides undergo amyloid-type aggregation, confirming that the APR segments from S100B undergo homotropic interactions that result in the formation of fibrillar materials. From BLI interaction experiments, we also concluded that those interactions may be recreated between the synthetic peptides and the corresponding regions in folded $\mathrm{S} 100 \mathrm{~B}$, as binding was detected. Finally, we established that those interactions reciprocally influence (co) aggregation phenomena. From aggregation kinetic experiments, we observed that APR-S100B peptides such as Pep6 have the potential to induce aggregation of S100B, while, for instance, Pep5 seems to engage in stabilizing interactions that inhibit its 
self-assembly. With this work, we therefore establish the proof of principle for the potential use of S100B-derived APR peptides as modulators of S100B function and bioavailability, which may constitute future promising tools for pharmacological interventions targeting S100B.

Supplementary Materials: Figure S1: HPLC chromatograms of the synthesized APR-S100B peptides.

Author Contributions: Conceptualization, J.S.C., J.S., F.R., and C.M.G.; formal analysis, J.S.C., M.A.R., R.G., J.S., F.R., and C.M.G.; funding acquisition, J.S., F.R., and C.M.G.; investigation, J.S.C., M.A.R., R.G., and F.R.; resources, J.S., F.R. and C.M.G.; supervision, J.S., F.R. and C.M.G.; validation, J.S. and C.M.G.; writing - original draft, J.S.C.; writing—review and editing, J.S., F.R., and C.M.G. All authors have read and agreed to the published version of the manuscript.

Funding: This research was funded by the Fundação para a Ciência e a Tecnologia through Grants UID/Multi/04046/2013 (BioISI), PTDC/NEU-NMC/2138/2014 (to CG), Ph.D. fellowship SFRH/BD/101171/2014 (to JSC) and SFRH/BD/114390/2016 (to MR). The Bial Foundation is acknowledged through grant PT/FB/BL-2014-343 (to CMG). JSC internship at KUL was supported by a FEBS Summer Fellowship, and MR internship at KUL was supported by an STSM Grant by the COST Action TD1304 - the Network for the Biology of Zinc (Zinc-Net). The Switch laboratory is supported by the Flanders institute for Biotechnology (VIB); KU Leuven; the Fund for Scientific Research Flanders (FWO, equipment grants AKUL/15/34-G0H1716N \& I011620N, project grant G0C2818N); the Stichting Tegen Kanker (FAF-F/201//1174); the Stichting Alzheimer Onderzoek (SAO-FRA 2020/0009).

Data Availability Statement: All data is presented in the manuscript.

Conflicts of Interest: The authors declare no conflict of interest.

Sample Availability: Not applicable.

\title{
Abbreviations
}

\author{
AD Alzheimer's Disease \\ A $\beta \quad$ Amyloid- $\beta$ Peptide \\ APR Aggregation Prone Region \\ ThT Thioflavin T \\ RAGE Receptor Advanced Glycation End Product
}

\section{References}

1. Donato, R.; Cannon, B.R.; Sorci, G.; Riuzzi, F.; Hsu, K.; Weber, D.J.; Geczy, C.L. Functions of S100 proteins. Curr. Mol. Med. 2013, 13, 24-57. [CrossRef] [PubMed]

2. Gonzalez, L.L.; Garrie, K.; Turner, M.D. Role of S100 proteins in health and disease. Biochim. Biophys. Acta Mol. Cell Res. 2020, 1867, 118677. [CrossRef] [PubMed]

3. Donato, R.; Sorci, G.; Riuzzi, F.; Arcuri, C.; Bianchi, R.; Brozzi, F.; Tubaro, C.; Giambanco, I. S100B's double life: Intracellular regulator and extracellular signal. Biochim. Biophys. Acta 2009, 1793, 1008-1022. [CrossRef] [PubMed]

4. Fritz, G.; Botelho, H.M.; Morozova-Roche, L.A.; Gomes, C.M. Natural and amyloid self-assembly of S100 proteins: Structural basis of functional diversity. FEBS J. 2010, 277, 4578-4590. [CrossRef] [PubMed]

5. Bresnick, A.R.; Weber, D.J.; Zimmer, D.B. S100 proteins in cancer. Nat. Rev. Cancer 2015, 15, 96-109. [CrossRef]

6. Cristóvão, J.S.; Gomes, C.M. S100 Proteins in Alzheimer's Disease. Front. Neurosci. 2019. [CrossRef]

7. McKnight, L.E.; Raman, E.P.; Bezawada, P.; Kudrimoti, S.; Wilder, P.T.; Hartman, K.G.; Godoy-Ruiz, R.; Toth, E.A.; Coop, A.; MacKerell, A.D.; et al. Structure-Based Discovery of a Novel Pentamidine-Related Inhibitor of the Calcium-Binding Protein S100B. ACS Med. Chem. Lett. 2012, 3, 975-979. [CrossRef]

8. Markowitz, J.; Mackerell, A.D., Jr.; Carrier, F.; Charpentier, T.H.; Weber, D.J. Design of Inhibitors for S100BCurr. Top. Med. Chem. 2005, 5, 1093-1108. [CrossRef]

9. Cirillo, C.; Capoccia, E.; Iuvone, T.; Cuomo, R.; Sarnelli, G.; Steardo, L.; Esposito, G. S100B Inhibitor Pentamidine Attenuates Reactive Gliosis and Reduces Neuronal Loss in a Mouse Model of Alzheimer's Disease. BioMed Res. Int. 2015, $2015,508342$. [CrossRef]

10. Cho, C.C.; Chou, R.H.; Yu, C. Pentamidine blocks the interaction between mutant S100A5 and RAGE V domain and inhibits the RAGE signaling pathway. Biochem. Biophys. Res. Commun. 2016, 477, 188-194. [CrossRef] 
11. Mori, T.; Koyama, N.; Arendash, G.W.; Horikoshi-Sakuraba, Y.; Tan, J.; Town, T. Overexpression of human S100B exacerbates cerebral amyloidosis and gliosis in the Tg2576 mouse model of Alzheimer's disease. Glia 2010, 58, 300-314. [CrossRef] [PubMed]

12. Cristóvão, J.S.; Morris, V.K.; Cardoso, I.; Leal, S.S.; Martinez, J.; Botelho, H.M.; Göbl, C.; David, R.; Kierdorf, K.; Alemi, M.; et al. The neuronal S100B protein is a calcium-tuned suppressor of amyloid-beta aggregation. Sci. Adv. 2018, 4, eaaq1702. [CrossRef] [PubMed]

13. Cristóvão, J.S.; Figueira, A.J.; Carapeto, A.; Rodrigues, M.S.; Cardoso, I.; Gomes, C.M. The S100B alarmin is a dual-function chaperone suppressing $\mathrm{A} \beta$ oligomerization through combined zinc chelation and inhibition of protein aggregation. ACS Chem. Neurosci. 2020, 11, 2753-2760. [CrossRef] [PubMed]

14. Rousseau, F.; Serrano, L.; Schymkowitz, J.W. How evolutionary pressure against protein aggregation shaped chaperone specificity. J. Mol. Biol. 2006, 355, 1037-1047. [CrossRef] [PubMed]

15. Beerten, J.; Schymkowitz, J.; Rousseau, F. Aggregation prone regions and gatekeeping residues in protein sequences. Curr. Top. Med. Chem. 2012, 12, 2470-2478. [CrossRef] [PubMed]

16. Betti, C.; Vanhoutte, I.; Coutuer, S.; De Rycke, R.; Mishev, K.; Vuylsteke, M.; Aesaert, S.; Rombaut, D.; Gallardo, R.; De Smet, F.; et al. Sequence-Specific Protein Aggregation Generates Defined Protein Knockdowns in Plants. Plant Physiol. 2016, 171, 773-787. [CrossRef]

17. Bednarska, N.G.; van Eldere, J.; Gallardo, R.; Ganesan, A.; Ramakers, M.; Vogel, I.; Baatsen, P.; Staes, A.; Goethals, M.; Hammarström, P.; et al. Protein aggregation as an antibiotic design strategy. Mol. Microbiol. 2016, 99, 849-865. [CrossRef]

18. Yanamandra, K.; Alexeyev, O.; Zamotin, V.; Srivastava, V.; Shchukarev, A.; Brorsson, A.C.; Tartaglia, G.G.; Vogl, T.; Kayed, R.; Wingsle, G.; et al. Amyloid formation by the pro-inflammatory S100A8/A9 proteins in the ageing prostate. PLoS ONE 2009, 4, e5562. [CrossRef]

19. Carvalho, S.B.; Botelho, H.M.; Leal, S.S.; Cardoso, I.; Fritz, G.; Gomes, C.M. Intrinsically disordered and aggregation prone regions underlie beta-aggregation in S100 proteins. PLoS ONE 2013, 8, e76629. [CrossRef]

20. Martinez, J.; Cristovao, J.S.; Sanchez, R.; Gasset, M.; Gomes, C.M. Preparation of Amyloidogenic Aggregates from EF-Hand beta-Parvalbumin and S100 Proteins. Methods Mol. Biol. 2018, 1779, 167-179.

21. Carvalho, S.B.; Cardoso, I.; Botelho, H.M.; Yanamandra, K.; Fritz, G.; Gomes, C.M.; Morozova-Roche, L.A. Chapter 18-Structural Heterogeneity and Bioimaging of S100 Amyloid Assemblies. In Bio-Nanoimaging; Uversky, V.N., Lyubchenko, Y.L., Eds.; Academic Press: Boston, MA, USA, 2014; pp. 197-212.

22. Fernandez-Escamilla, A.-M.; Rousseau, F.; Schymkowitz, J.; Serrano, L. Prediction of sequence-dependent and mutational effects on the aggregation of peptides and proteins. Nat. Biotechnol. 2004, 22, 1302-1306. [CrossRef] [PubMed]

23. Beerten, J.; Jonckheere, W.; Rudyak, S.; Xu, J.; Wilkinson, H.; De Smet, F.; Schymkowitz, J.; Rousseau, F. Aggregation gatekeepers modulate protein homeostasis of aggregating sequences and affect bacterial fitness. Protein Eng. Des. Sel. 2012, 25, 357-366. [CrossRef] [PubMed]

24. De Baets, G.; Van Durme, J.; Rousseau, F.; Schymkowitz, J. A Genome-Wide Sequence-Structure Analysis Suggests Aggregation Gatekeepers Constitute an Evolutionary Constrained Functional Class. J. Mol. Biol. 2014, 426, 2405-2412. [CrossRef] [PubMed]

25. Schrodinger, LLC. The PyMOL Molecular Graphics System; Version 1.8.; Schrodinger, LLC.: New York, NY, USA, 2015.

26. Gade Malmos, K.; Blancas-Mejia, L.M.; Weber, B.; Buchner, J.; Ramirez-Alvarado, M.; Naiki, H.; Otzen, D. ThT 101: A primer on the use of thioflavin T to investigate amyloid formation. Amyloid 2017, 24, 1-16. [CrossRef] [PubMed]

27. Klingstedt, T.; Aslund, A.; Simon, R.A.; Johansson, L.B.; Mason, J.J.; Nystrom, S.; Hammarstrom, P.; Nilsson, K.P. Synthesis of a library of oligothiophenes and their utilization as fluorescent ligands for spectral assignment of protein aggregates. Org. Biomol. Chem. 2011, 9, 8356-8370. [CrossRef] [PubMed]

28. Concepcion, J.; Witte, K.; Wartchow, C.; Choo, S.; Yao, D.; Persson, H.; Wei, J.; Li, P.; Heidecker, B.; Ma, W.; et al. Label-free detection of biomolecular interactions using BioLayer interferometry for kinetic characterization. Comb. Chem. High Throughput Screen. 2009, 12, 791-800. [CrossRef]

29. Ostendorp, T.; Leclerc, E.; Galichet, A.; Koch, M.; Demling, N.; Weigle, B.; Heizmann, C.W.; Kroneck, P.M.H.; Fritz, G. Structural and functional insights into RAGE activation by multimeric S100B. EMBO J. 2007, 26, 3868-3878. [CrossRef]

30. Thulin, E.; Kesvatera, T.; Linse, S. Molecular determinants of S100B oligomer formation. PLoS ONE 2011, 6, e14768. [CrossRef]

31. Fields, C.G.; Lloyd, D.H.; Macdonald, R.L.; Otteson, K.M.; Noble, R.L. HBTU activation for automated Fmoc solid-phase peptide synthesis. Pept Res. 1991, 4, 95-101. 